Communities of Practice in Art and Design and Museum and Gallery Education.

\title{
STEVE HERNE
}

Goldsmiths College, University of London, United Kingdom

\section{Abstract}

This paper draws on a wider body of research which explores whether art and design teachers (art teachers) and museum and gallery educators (gallery educators) hold conflicting conceptions of 'critical and contextual studies'. The data analysed focuses on what interviewees said about each other in relation to crossing boundaries between institutions, subject and pedagogical content knowledge, conceptions of the discipline of art and design, the role of gallery education in curriculum development and influence over the development of the pedagogical identities of students. The social theories of communities of practice (Lave \& Wenger, 1991; Wenger, 1998), discourse (Laclau \& Mouffe, 1985; Howarth, 2000) and boundary objects (Star, 1989) are used to explore and conceptualise the complexity of the interaction between the two groups. The paper concludes that trans-institutional and inter-professional communities of practice can be established which have the potential to generate new forms of engagement, shared repertoire and joint enterprise. 


\section{Communities of Practice in Art and Design and Museum and Gallery Education.}

\section{STEVE HERNE}

Goldsmiths College, University of London, United Kingdom

\section{Introduction}

'Critical and contextual studies' is a term currently used by art teachers in schools in Britain to describe the area of art and design education which complements and supports pupils' individual art making by providing a reflexive theoretical background to ongoing creative development. It is a process grounded in critical, contextual, aesthetic and art historical enquiry. Art teachers and gallery educators both have a role in developing students' understanding in this area. Schools, and museums and galleries in Britain now share the responsibility but this shared responsibility is differently balanced. Schools have a statutory duty to provide a systematic art education for all children from the age of 5 to 14 (with further options from ages 14 to 19), while museums and galleries provide a resource that is available by choice to diverse audiences, including school students. However, many museums and galleries education departments are either required, or feel a special responsibility, to work with students and teachers in the formal sector while serving and developing their multiple audiences. Government policy has regularly directed public money through agencies such as the Arts Council of Great Britain and the regional Arts Boards and their successors, towards encouraging gallery educators to become active in this area. Gallery educators have also encountered problems in dealing with an increasing demand for their input directly from school students. If art teachers and gallery educators are going to work successfully together it would seem helpful that they develop a greater understanding of the ways in which each other characteristically think, speak and interpret in this area and how their discourses and 
practices differ despite sharing a common focus in art education. In this paper I intend to explore firstly the social theory of communities of practice, followed by a brief description of teachers and gallery educators and their differences. I will then go on to discuss the findings of the research study in relation to boundaries and crossings between the two groups, pedagogical knowledge, views of art in relation to disciplinary structure, the potential for curriculum development, and the modelling of students' identities. I will conclude by exploring the potential for engagement and enterprise promoted by an understanding of the social processes of communities of practice.

\section{Communities of Practice (CoPs)}

Its easy to see art teachers and museum and gallery educators as two distinct communities who can be recognised by their characteristic practice. Wenger (1998) observes that despite being a novel concept, 'communities of practice' are integral to our experience of our daily lives and therefore familiar. We are all members of many, often overlapping communities of practice, for instance: a circle of friends who share an activity, an internet community, or a local group of supporters of a well known football team. More delineated groupings can be found in our professional contexts. Indeed, in schools, there are many overlapping communities of practice: playground cliques, after school clubs, office secretaries, support staff, groups of teachers, or in galleries: curators, audience groups, guards, senior management etc.

However, not all communities are 'communities of practice'. The three key dimensions of mutual engagement, joint enterprise, and shared repertoire are all necessary conditions for recognition in this theoretical construct (Wenger, 1998). Communities of practice are not therefore necessarily synonymous with institutional categories. People who work alongside each other in a department without mutual engagement cannot be said to be part of a community of practice. Additionally, 
people can be mutually engaged across institutional boundaries developing joint enterprise and shared repertoire, forming trans-institutional communities of practice. Membership of a community of practice is therefore elective, requires acceptance and is characterised by participation. Commercial or public institutions or other social configurations as a whole are often too large or complex to be treated as single communities of practice and must therefore be regarded as 'constellations' of interconnected or overlapping communities of practice (Wenger, 1998, pp. 126-128). Lave and Wenger acknowledge the negotiation of meaning and the production and reproduction of knowledge inherent in the processes of a community of practice and sum them up as

..... a set of relations among persons, activity and world, over time and in relation with other tangential and overlapping communities of practice. A community of practice is an intrinsic condition for the existence of knowledge, not least because it provides the interpretative support necessary for making sense of its heritage (1991, pp. 98).

\section{Parallel Communities of Practice in Discourse Communities}

Art teachers are potential members of overlapping communities and constellations of communities of teachers. These include those in their own institution such as staff room friendship groups and the subject department to which they belong. They also may well be members of their specialist subject community which is transinstitutional, national and possibly international. Gallery educators similarly are potential members of the constellations of communities of all museum and gallery educators. They may belong to the communities of their discipline field (history, science, art etc.) or to more specialised communities formed around specific focuses: contemporary art or antiquities etc. A group of teachers in an art department engaged in mutual enterprise forms a community of practice that is parallel to communities of practice of groups of art teachers in art departments in other schools. While these 
parallel groups are not united directly in mutual engagement or joint enterprise they still have much in common and share a repertoire of ways of working and language born out of their parallel enterprise in educating young people in their shared subject specialism. Laclau \& Mouffe's (1985) conception of discourse is not restricted to linguistic phenomena but embraces all social practices and relations. In relation to this definition, parallel communities of art teachers share a wider art education discourse constituted by the language and shared experience of their training; the curricula and syllabi which they must interpret; and their shared repertoire of educational practice developed through experience and social interaction. This gains approval and is shaped through success or failure in examination moderation and is subject to the surveillance of inspection with its disciplinary regime of praise and sanctions. Finding a 'common enemy' (perhaps in the form of the inspection service) provides a site for the development of community solidarity. This is illustrated by Goodson (1985), who, while exploring case studies of curriculum history, draws attention to the precipitatory effect of inter-institutional conflict in the formation of professional subject associations. While not directly engaged, nevertheless department groups share common interests, concerns, and discourse.

Gallery educators can form communities of practice within their own institutional and departmental structures. However, the smaller the institution, or if there is only one education officer in an institution, the more likely it is that communities of practice will form across institutions. Each local community interprets the broader discourse and develops its own practice and style. This is shared and appropriated through contact between communities of practice. Some members of local communities of practice may reach out and become members of trans-institutional communities through engagement and participation, forming or joining of associations or societies, attending conferences etc. If we accept that all are united by membership of their discourse community, local communities of practice of art teachers and gallery 
educators could each be theorised separately as members of constellations of parallel communities of practice united in discourse communities.

\section{Constructing Identities}

As communities are the contexts in which identities are formed, newcomers are faced with the paradox of needing to engage in characteristic practice in order to be recognised as full participants while at the same time wanting to establish their own unique identity and original contribution to the future development of the community (Lave \& Wenger, 1991). Communities of practice exist in a wider social field which itself is in a constant state of flux; therefore the processes of reproduction are always accompanied by the processes of change (Wenger, 1998). Communities of practice overlap and interact with others with continuity and discontinuity; contestation and cooperation; antagonism and attraction. If communities of practice are the sites for construction of identity, they are also used by those outside as a shorthand source of recognition and generalisation for those perceived as members. It becomes possible to identify individuals as 'teachers' or 'art teachers' or 'museum and gallery educators' with specific characteristics and traits, positive or negative tendencies. Recognisable communities of practice become 'objects' with homogeneous characteristics to those outside. It becomes possible to say 'teachers do this' or 'gallery educators think that'. While this process is crucial in rendering bewildering complexity manageable, the simplification can also be crude, misleading, stereotyping, and has to be negotiated critically.

\section{Boundaries}

Once communities are recognised as entities it becomes evident that there will be boundaries. While art teachers and museum and gallery educators both form part of the discourse community of all 'art educators' their day-to-day identities are bound up in the experience and practice of their narrower group. Communities of practice do 
not exist in a vacuum but overlap and interact with others. There are areas of mutual concern and engagement shared by communities across boundaries. 'Boundary objects' (Star, 1989) provide a mutual focus of interest around which communities of practice can co-ordinate their interaction and enterprise. In the case of the two groups studied, the art works located in exhibitions and collections and mediated through art books, television and the internet, are the most obvious boundary objects which bring the two communities of practice together. Teachers' packs and websites are boundary objects produced by gallery educators, designed to flow into the practice of art teachers. Teachers' evenings are 'boundary events' where dialogue and interaction are possible, where power relations are played out and alliances formed. School visits to museums and galleries are special boundary events involving professional collaboration, as are gallery outreach projects where the tentacles of the institution are spread out into the community encouraging activity both in the school and gallery sites (Herne, 2001; Amidu, 2001). The identities of school pupils and students modelled by each group can also be seen as boundary objects. They are the shared foci for investment and transaction, a target audience which each group plans for and acts with, and whose development it ultimately judges its success by. As each community of practice maintains and develops a unique discourse then this in turn will lead to the projection of differently modelled pedagogical identities on to students. Like the varied and multiple interpretations of artefacts by audiences in the gallery these living subjects, the students, are subject to differentiated interpretation, expectations and practice as learners. Their pedagogical identity can, therefore, become a site of contestation or negotiation between the two groups of educators.

The research on which this paper draws set out to find out if art teachers and gallery and museum educators hold conflicting paradigms of critical and contextual study. By investigating the discourse of each of these sets of parallel communities of practice through the analysis of the data acquired through semi-structured interviews, some 
insight may be gained into the motivation and characteristic ways of thinking of each group, with particular focus on their thoughts about, and interaction with, the shared enterprise of art education. To generalise, they will often define themselves as separate groups and have distinctly different backgrounds, experience, practice and discourse, although research in London (Herne 1998) suggest that there is often a fluid career combination of the roles of artist, teacher and gallery educator, particularly amongst freelance and part-time workers. Before discussing the findings of the research study I will provide brief descriptions of gallery educators and art teachers

\section{Gallery Educators and Art Teachers}

In the UK, gallery educators are typically drawn from art historical backgrounds and work closely in their institutions with curators and publicity departments. One of their roles is often described as providing 'interpretation'. Since the development of the new art history (Rees \& Borzello, 1986; Harris, 2001), interpretation has become a highly contentious issue in the museum and gallery field around which there are constant debates. These debates inform the role ascribed to the audience and the power relations between the audiences' potential to construct their own interpretation and the authority attributed to the 'voice' of the institution or curator. So far I have treated gallery educators as one community but there are differences between museum education and gallery education. The overlap is strongest where the common focus is art and visual culture and it is on this particular community that I focus in this research. There is also no consensus about what defines gallery education. As McKenzie asks: 'Is it exclusively about contemporary art or does it encompass art of the past? Is it primarily about art making or art history? Is it about pedagogy or creative activity? There is a debate about what lies at its very centre; the art object, the artist or the learner' (2001, pp. 22). An answer is that it is probably 
about all of these things and a few more besides, produced in a complex flow through the practice ot the community of gallery educators.

Gallery educators are most often art history graduates and will often be in touch with cutting-edge critical and curatorial theory through its practice in their institution, through professional networks and through part-time postgraduate courses. Their main practices involve writing, discussion and project management. However, some contemporary art galleries make extensive use of artists because of their special and first-hand, understanding of the artistic process. Artists are also more likely to be engaged where practical workshop activities are an important aspect of the education service. To complicate matters further, museums and galleries sometimes target recruits who have a teaching background for posts which have a specific remit for liaison with schools.

An important activity for many gallery educators is the preparation of bids to government agencies, funding bodies, and charitable foundations. They need to be adept at articulating their aims in ways which will seem attractive to the different expectations of funding bodies. This involves a careful analysis of specific funding criteria and an authoritative command of arts funding discourse as well as an awareness of contemporary issues and policy. This necessity to bid for funds to finance education services, together with the inevitable requirements of evaluation and reporting back, means that gallery educators are constantly clarifying aims and writing rationales. They are therefore usually more conversant with theory than those involved in formal school-based art education who, it can be argued, are more involved in promoting art practice and the processes of its assessment.

In Britain art teachers in secondary schools (ages 11 - 19) usually study for their first degree - a fine art, craft or design-based course at art college, - followed by a year of 
teacher education - a post graduate certificate of education (PGCE) course. Art degree courses are primarily concerned with art, craft or design production although the percentage of time devoted to theory is increasing, moving from an approximate $80 \%$ practice $-20 \%$ theory split to $60 \%-40 \%$ split in some contemporary fine art courses. Some art teachers continue to practice as artists, craftspeople or designers, although it is difficult to combine this with a full-time teaching role. Teachers therefore share a background of practical and theoretical engagement with artists but not so much with museum and gallery educators from an art history background.

In England and Wales it is necessary for teachers to integrate or negotiate between, their own understandings and educational aims and the frameworks and expectations of the National Curriculum and examination syllabuses. Compliance with the National Curriculum is subject to the surveillance the Office for Standards in Education (Ofsted), while conformity with syllabuses requirements, evidenced in end of course examination submissions, is subject to external examination and moderation organised by the National Examination Boards. Another influential process is the necessity for teachers to assist school students to prepare portfolios for entry in to art college. This is an activity which is usually viewed positively as art teachers feel solidarity with the art colleges and derive satisfaction from the recruitment of their students into the same broader art education community they joined. Less positively, teachers are subject to increasingly oppressive institutional pressure in the pursuit of raising educational achievement and standards, as schools respond to the competitive context of league tables; targets for exam success and the threat of failure during inspections. The focus of this pressure is on examination success rather than the quality of art educational practice, although this is often assumed to mean the same thing. The increased bureaucracy in secondary education in a culture of accountability, manageralism and target setting, may well be at odds with the art teachers own values and preferred modes of practice (Bennet, 1985). 
Briefly some of the broad differences between the two groups can be summed up as follows. Apart from key leadership roles in leading 'Flagship' institutions, gallery educators are lower paid and many posts are temporary or fixed term, compared with the 'tenure' enjoyed by art teachers. However, teaching is a mass profession - there are thousands of art teachers, while there are fewer gallery educators across the country. Because of the connection with the museum or gallery institution as opposed to the school, work in gallery and museum education is often regarded as higher status (more unique, more unusual) than that of the teacher. Gallery work is seen as varied and interesting while the work of the art teacher more routine. Despite the higher pay enjoyed by art teachers, the higher status enjoyed by gallery educators is available as cultural capital which can be employed in power relations between the two groups. In British schools there are slightly more female secondary teachers than male across all subjects in the curriculum, while in art and design the proportion of female to male teachers is much higher, moving from approximately 3:1 currently to 3.5:1 based on recent recruitment figures to Initial Teacher Training (GTTR, 2003). In Gallery education attendance at gallery educators meetings suggest that the proportion of female to male is equally high or higher in this field, an impression born out by informal enquiries to a gallery educators' national association. It could be argued therefore that both professions are 'feminised' (Dalton, 2001).

At the risk of oversimplifying a complex field, it is possible to hypothesise that in relation to pedagogy gallery educators privilege talk: the lecture, the guided tour, the discussion and the seminar; while the art teacher privileges investigating and making, the physical and creative processes of art production. In relation to interpretation, gallery educators privilege personal response and art as experience, seeing students as audience and critics, while art teachers privilege art as a repository of ideas, genres and styles, models to expand the possibilities of the visual language and 
expression of their students as artists. It was with these broad characteristics in mind that the research study was designed to reveal evidence of differences in attitudes and discourse between the two constellations of parallel communities of practice.

\section{The Research Study}

The small-scale research study explored the differing understandings and perceptions of the two groups cross-referenced with additional material from others who in some way influence or have access to the context in which these two groups meet and interact. This included interviews with teacher educators involved in Initial Teacher Training (ITT) and an Art Chief Examiner. The broad aim of the research was to explore the, perhaps conflicting, paradigms of critical and contextual studies held by art teachers and gallery educators. This involved conducting seven semistructured interviews which were recorded. Typescripts were prepared and analysed to reveal emerging emerging themes and support the development of theory grounded in the data (Glaser \& Strauss, 1967). The limited size of the group of respondents precludes any extended claims of generalisation. What I am able to do is to highlight indicative issues arising from the analysis of the research data and construct a narrative which begins to interpret interviewees' responses in terms of resonant theory. The two groups are theorised as communities of practice implying separateness and therefore boundaries, as well as the possibilities of overlap. These boundaries are metaphorical rather than physical although clearly schools and galleries as sites are almost always separated physically. I will begin by exploring the physical space which exists between the two sites, its effects and measures taken to overcome them, before moving on to explore teachers' and gallery educators' perceptions of each others' pedagogical knowledge, art as a discipline, curriculum development and students' pedagogical identities.

\section{Crossings Boundaries}


Art teachers and gallery educators have a clear physical divide as they belong to institutions with very different public functions. Both groups are keen to encourage school students to experience the art held in galleries and museums at first hand. For gallery educators this is a central focus of their community of practice, while for teachers it is a desirable yet peripheral aspect of their practice. There are organisational and geographical issues which cause problems. Teachers organise group visits to museums and galleries and as students get older the focus changes to encouraging and developing patterns of independent gallery visits. There are a number of practical issues to do with travel, time and cost which can work against the enthusiasm for gallery visits.

Some of the students will go on a gallery visit of their own. I say this, that very few of our students have the initiative to go off to galleries on their own. We are not able to take as many students out to galleries as we would like. We are in an awkward position. We are fairly close to London but we are just too far away to make it practical to get there easily. To get to the nearest station we have got a three-quarter of an hour's walk, which is fine on a sunny day but is not good in Winter, if there is a chance of it pouring. A coach trip from here to London is remarkably expensive. There are also problems in school generally of getting students out all day to galleries... Although we frequently go with sixth form students to galleries we less frequently go with students in other years. I would like to see us do that more often. It just is the pressure on schools, on targets these days throughout the school and the exam results. It means that other departments are less and less happy for you to take students out of their lessons. If we can't go to galleries we tend to bring the galleries here by exposing the kids to as many as possible examples of artist's work. (teacher) 
Galleries have a number of strategies to bridge the gap and encourage visits. One is to create a special area within an institution, an education room, space or gallery area where diverse activities can take place. However, the lack of provision of suitable facilities strengthens the hypothesis that the communities of practice of gallery educators privilege talk (critical discourse) over making (art production) as a medium for education:

Only 36\% had a general teaching room and less than 10\% had a practical art or photography studio or a children's gallery (Anderson, 1997, 1999).

If visits are a rarity thought also needs to be given to the quality and focus of the experience for the audience:

Going to a gallery [or art museum] can be a one-off, abrupt, clinical experience. At the [Gallery C], the narrative of art may be changing all the time, but the student experiences it as an authoritative story. Galleries can do more to expose the way they question the narrative. (gallery educator)

Further, it is only with familiarity that an awareness of institutional process develops as this teacher testifies:

I have memories of significant moments for example, seeing the Doge of Venice in the National [Gallery], all brown, then later bright blue. I realised that galleries did other things than just put art on the walls, they also look after it. The impact of those gallery spaces!

Few galleries educators or teachers think consistently about deconstructing the processes of the institution itself by giving young people or other audiences access to 
an understanding of all the branches of the gallery practice including: programming, curating, restoration, marketing, security, catering, shopping, etc., and choose to focus rather on their primary raison d'etre: encounters with artefacts, interpretation and education. The former practices, some of which remain invisible, provide a frame and context within which gallery educators engage and develop their own practice. Without understanding these institutional processes, particularly how curatorial and marketing practice create 'authoritative stories', teachers' understanding of the role of museums and galleries and the discourse of their education departments is limited. In turn, the student's power to understand and make personal interpretation is also limited.

Galleries, however, particularly their education departments, make great efforts to engage their audiences. Support materials: mailings, teachers' packs, booklets, catalogues and websites provide contextual information. In terms of community of practice theory (Star, 1989), these material resources can be identified as boundary objects. Lee Star used the term boundary objects to describe things which function to co-ordinate the different perspectives of various constituencies. A teachers' pack contains statements of value by the originating education department and associated contextual information; these in turn are reinterpreted and appropriated by its intended audience. Inservice training (INSET), teachers' evenings and private view events run by gallery educators encourage the development of networks, contacts, and inform teachers. These can be identified as boundary events and provide opportunities for boundary practices, the beginnings of mutual engagement and perhaps a starting point for a joint enterprise. Given time this work of connection can become a practice in its own right and provide a medium for the development of a new trans-institutional, inter-professional communities of practice.

\section{Pedagogical content knowledge}


The notion of pedagogical content knowledge was introduced by Shulman (1986) who defined it as including knowledge of children's misconceptions, successful teaching strategies, analogies, demonstrations and explanations which are most beneficial in developing childrens' understanding. 'Successful' teachers partially develop pedagogical content knowledge through initial training and then through interaction in communities of practice formed in the classroom, as well as through contact with more experienced practitioners in the community of teachers. For example, successful art teachers know how to help students develop ideas and individual artwork over time through an open-ended process of research, investigation, experimentation and making, sustained through an ongoing dialogue or 'conversation' in the familiar context of the studio. However, gallery educators, like teachers, develop their own different pedagogical content knowledge in relation to their own sites, characteristic audiences, processes and activities which is equivalent but qualitatively different to that of art teachers. This might involve, for example, the knowledge of how to 'break the ice' with a new group in a novel context in the gallery, present key concepts and initiate and sustain visual investigation, discussion and interpretation through carefully chosen questioning. It is, perhaps, unreasonable to expect too much of gallery educators who often meet new groups only for short periods of time. It is a realisation of this factor which often leads museums and galleries to employ educators with training and experience in schools or artists to run workshops with school students. It has also led some museum and gallery departments to recognise the childrens' teacher as their best teacher and concentrate their resources on developing partnership and training to support teachers to gain confidence to work in the gallery context (McKenzie, 2001). This, however, was not perceived by the teachers.

One of the key issues in the research data highlighted teachers' perceptions of gallery educators' lack of pedagogical understanding of childrens' development and 
their application of specialist knowledge in teaching and learning contexts. Some of the following quotes illustrate the stereotyping and lack of respect which sometimes characterises both groups, although these were often balanced by positive statements, (sometimes from the same respondent!)

Well, what do they [gallery educators] know about what goes on in schools, nothing!

Some of the gallery educators may not have any training in pedagogy.

The people who are running gallery education are not necessarily aware of the pedagogy of the classroom at all.

(Gallery educators are) patronising, talking above their heads, (they) haven't any idea what children are, what they know or understand. I was watching the people with the younger children, they seemed to be better but I suppose they're hand picked, exprimary teachers or something, but some are awful,

In turn, gallery educators often refer to their perception that teachers lack understanding of contemporary art and its practice, implying a lack of subject knowledge (and teachers are often ready to accept this as will be explored in the next section). It is often this perception which motivates gallery educators to develop projects which can help teachers to develop new understanding, critical approaches to working with art and provide models of practice. However, there can be a recognition that teachers have greater pedagogical knowledge of their students and are therefore more able to find appropriate ways of communicating with and teaching them, as is illustrated by the following quotation: 
Galleries would be mortified if they were deemed to be rude etc. They do recognise that the best people to teach groups are the teachers themselves but in partnership with artists and gallery educators. [Gallery A] is starting a schools in partnership scheme to build communication and team teaching so it isn't just a rushed, impersonal tour. (gallery educator)

If, as Lave and Wenger argue, communities of practice are an intrinsic condition for the existence of knowledge (1991, pp. 98) then the production, maintenance and reproduction of pedagogical content knowledge can be seen as part of the essence of the two communities practice. In terms of discourse and communities of practice theory, pedagogical content knowledge can be identified with both the shared repertoire of language, social practices and relations of the wider discourse community and the more local body of practice: the knowledge and skills reproduced and developed within the community of practice itself. If gallery educators' practice tends to privilege the spoken word and gallery-based processes of experience, response, interpretation, and discussion, while art teachers practice is much more grounded in the creative studio-based processes of art production, the dissonance in the area of pedagogical content knowledge is not surprising.

\section{Art as a subject, art as a cross-disciplinary process}

In England and Wales, art in schools is clearly identified as a subject (currently called Art \& Design), a cognate area with its own characteristic processes and procedures and physical studio space. Broadly, a modernist conception of art as a refined, universal, purist discipline with its grand narratives of progress has yet to be fully overtaken by a more post-modern vision of a pluralist, interdisciplinary, intercultural and multi-sited enterprise, although we are clearly in the process of a paradigm shift (Kuhn, 1962; Efland, Freedman et al, 1996). Gallery educators see this area of disciplinary definition as a major area of difference. 
Art and design teachers define their subject as a discipline, whereas gallery educators often wish to break its boundaries and work across the curriculum. (gallery educator)

Well to be truthful there aren't enough partnerships between gallery education and curriculum bodies.... it can't be fruitful either because the curriculum is so hamstrung by being so subject-based and not interdisciplinary enough. (gallery educator)

Teachers would accept that there are significant institutional difficulties to crosscurricular liaisons in secondary schools in Britain.

You might talk to another teacher informally and try and link it in, but the cross curricula stuff is very, very difficult to actually do because of time and time-tabling, especially when the National Curriculum stuff came in. (teacher)

At the same time as accepting the subject-based nature of their enterprise, many art teachers have responded to the same cultural zeitgeist which influenced the development of the new art history. Some have made efforts to make the art curriculum more inclusive and respond to the interests of bicultural or multicultured students in the classroom by taking on a global perspective to the study or art and culture (Mason, 1990). Others have responded to the influence of critical feminism and the gender equality movement (Dalton, 2001). This has resulted in an increasingly pluralist and diverse curriculum (Dalton, 2001) and amongst a variety of foci, an interest in 'issue-based' projects which push beyond formalism and aesthetics to an art that reflects personal, social and/or wider political concerns. 
.....but issued-based [project work] is part of what we're doing all the time, especially when using textiles.... using all our resources to try and put into context for the students, to understand where the things come from and the exploitation of a lot of the workers who had made them..... or identity projects... that deal with abuse or racism...(teacher)

This kind of work mirrors the interdisciplinary approach that the gallery educators would value and perhaps the lack of appreciation of the achievement of this kind of art and design work in schools is due to its invisibility to anyone outside the institution or the assessment moderation process. There are few opportunities to see this work, as it is rarely publicly exhibited. Another factor may involve the lesser experience of teachers in articulating theoretical rationales for their practice explored earlier, and their reticence in the face of expertise explored in the next section. It is not common for communities of art teachers to disseminate either the practice of their students or their own rationales. The perceived narrowness of the school art curriculum remains, therefore, part of the mythology in the discourse of gallery educators.

\section{Art History Knowledge}

Teachers like anyone else are limited by their own predilections, cultural references and training and this will be reflected in what they chose to do and are able to do with students in the classroom and their discourse and practice. Generally teachers defer to gallery educators seeing them as experts in art history and cultural studies. Despite the wide range of knowledge and understanding that many teachers amass over time in the domain, they remain modest about their facility in this area, particularly in the presence of those they see as having greater expertise.

20th Century is a .... strength, anything before that is a definite weakness, anything before 19th Century would be fairly weak. (teacher) 
I like to use cross-cultural resources as much as I can, what worries me is when I do is how much I'm just skimming across the surface because I don't really understand either the symbolism in it or the content. I'm just dealing with it on a relatively superficial level so that is a weakness. (teacher)

This 'weakness' seems to be one of the characteristics of art teachers' discourse, perhaps due to their greater identification with art production and their training as artists, designers or craftspeople. It seems to be one of the real motivators that engages teachers in making connections with museum and gallery educators. They see that there is a potential to go beyond their perceived limitations, to engage themselves and their students in contemporary or unfamiliar critical practice. They can give their students a taste of 'real art', they can take risks, destabilise and refresh well worn successful practices that are becoming too familiar. There is a chance to interact with other professionals, to learn and develop themselves. This fits in well with gallery educators' identity discourse as experts and agents of curriculum development.

\section{The curriculum development role of museum and gallery education}

Assuming that many teachers are 'behind the times' or lack expertise, many gallery educators see a role for themselves in curriculum development to impact on what goes on in schools. This is beyond their more obvious responsibility for the interpretation of collections and temporary exhibitions to diverse audiences. There is some cynicism about the motivation and expectations of schools and little respect for discourses of school improvement and the manageralism inherent in target-setting agendas (the latter position is shared by the majority of art teachers!) 
Schools expect galleries to provide resources geared towards improving exam results, so that schools can go higher in the league tables. (gallery educator)

Communities of gallery educators maintain a discourse of expertise in relation to art teachers which extends to a belief in their potential to influence, improve and change the curriculum.

Gallery education offers something different from what goes on in schools that some teachers seem to find extremely refreshing... expert others. (gallery educator)

Museum and gallery educators have potential for improving and changing the curriculum. (gallery educator)

Teachers may not see the direct relevance of gallery educator-led curriculum development in their own sphere of practice but rather see museum and gallery education as a resource, both in terms of interpretation and in specific areas such as the development of critical language:

I think their role in interpreting their collections to as many schools that can make use of them is an essential one. That does not exclude the odd exciting project for which they get a bit of extra funding ..... (teacher)

most [museum and gallery educators] do not come from teaching backgrounds....... they speak a different language. It is a language that ' $A$ ' level students should start to get familiar with...... though it is not a language younger students would necessarily understand. (teacher) 
Here the teacher is identifying the different discourse of gallery educators as something which may be a barrier to communication with younger children but valuable at the age of $16-18$ at a higher level of specialism. Nowhere in our interview data did teachers indicate that gallery educators could be a source of general curriculum development for art teaching in schools.

In her paper 'Working with Schools on the Problems of Looking', partially drawing on some of the same data used in this paper, McKenzie approaches the issues from the point of view of the gallery educator. She acknowledges the importance of making and doing in gallery education but privileges looking, talking and thinking as the essential ingredients (2001, pp. 24). She focuses on the development of learners' encounters with art and proposes supporting them through the use of a variety of strategies to develop hypotheses, personal interpretations and thinking skills which can take them beyond initial personal responses. McKenzie is keen to share experimental strategies and models with teachers and emphasises the value of partnership in developing the quality and ambition of work in this area both at the site of the school and in the gallery. She is quite precise about the area in which gallery education can contribute:

Gallery education.... has a role to support schools in becoming more structured and rigourous in working with art, by offering spaces for reflective practice, by testing new methodologies and by expanding the canons. (McKenzie 2001, pp. 22)

If the broad focus of this is essentially to develop the students' identity as critics then this dovetails well with the art teachers' project to develop students' identity as artists and critics, although the critical process is understood as an element in the dialectic of art production. This pedagogical identity of artist and critic is enshrined in the rhetoric of the assessment objectives in current examination syllabi (AQA, 2000). 


\section{Communities of practice and the quest for influence over students' pedagogical identity}

To conclude this exploration of the differing understandings and perceptions of the two groups I will now explore how the modeling of the students identity differs between the two constellations of communities of practice, and how their identity is a site of contestation but also of potential collaboration. It is clear from the earlier comments of teachers that they perceive gallery educators' lack of pedagogical knowledge without necessarily recognising the gallery educators' own different areas of relevant pedagogical knowledge. It has also been suggested that within the gallery educators' own communities of practice, art criticism and the processes of looking, talking and thinking are essential elements of discourse. Gallery educators will model the identities of students in these terms but are often dependant on art teachers (who could be seen as gatekeepers to access) to provide their audience. Art teachers value the close social relationships formed with their students (Bennet, 1895) which are essential for their own development of pedagogical knowledge in the processes of the classroom. The successful school art class can itself be theorised as a community of practice with shared enterprise, engagement and developing repertoire, as students develop their identities and learn in apprenticeship mode from the teaching 'old timer'. The art teacher, however, is a special kind of practitioner and the practice in development is art rather than art teaching. Gallery educators also want to influence the construction of the identities of students but can meet with resistance, as the following quote encapsulates.

I want to see teachers lose their preciousness over their sixth form art groups. They are very protective of them because there are often so many challenges to getting the course accepted. They can develop a very close relationship with the group, partly because of the nature of the material they teach, partly because they have fun going 
on visits and the art room is relaxed. But they have to go one stage further by trusting the group with someone else, with other specialists. (gallery educator)

A characteristic of the processes of a community of practice is that strategies are used to either promote or prevent access. This is a play of power relations and can be relatively transparent or opaque. With many of its audiences the gallery education department can reach out directly to participants but with formal education it needs a relationship with art teachers for access. This is at least until students have formed gallery going habits and are old enough and confident enough to make independent visits. However, with an overlap in the interest in the production of the student identity as art critic and a mutual focus on the art collections as boundary objects, there would seem to be grounds for collaboration and shared enterprise between teachers and gallery educators. This is common ground, a genuine overlap of boundaries between the two communities of practice.

\section{Conclusion}

Given the interest of art teachers in engaging pupils and students in encounters with real art and the ambition of gallery educators to contribute to and influence schoolbased curriculum development, how can the theory of communities of practice help us understand the relationship between art teachers and gallery educators and the discourses and practices which unite and divide them?

Art teachers and gallery educators were theorised as belonging to constellations of parallel communities of practice within wider discourse communities. Although united in the wider discourse community of art education, the two groups are divided geographically and institutionally, and more specifically by discourse and practice. Despite separation the two communities of practice share interest, investment and involvement in developing the art educational identities of pupils and students 
studying in formal education. Areas of overlap and spaces for engagement, negotiation, and shared enterprise exist particularly in the area of developing the identity of the student as critic. These are mediated through a variety of boundary objects, events and practices.

The role of the broker seems an important one in negotiating constructive partnerships, involving a complex process of co-ordinating, translating and aligning between the perspectives of the teachers and gallery educators. A successful broker has recognisable legitimacy in both communities and understands enough about the discourse and practice of each group to gain attention, negotiate participative space and facilitate engagement (Wenger, 1998). On reflection it becomes clear that this role can be performed by anyone who spends time developing legitimacy at the boundaries of a community of practice. This could include the art teacher who regularly uses gallery and museum education resources, the gallery educator who takes time to get into schools, to observe and talk to teachers, or more formally, the project organiser working for an arts-in-education agency who liaises between different sites, groups and professionals. Activities might involve facilitating planning meetings where members of different groups can interact, begin to learn each other's discourse, engage and develop a shared enterprise. Artists have been identified as providing a brokering role in some cases, partially sharing identity with teachers through their expertise in art production, and enjoying sufficient legitimacy in both communities to facilitate engagement and enterprise.

However, issues of power relations, status, opacity/invisibility of practice and access have been identified and both groups need to become more aware of how the power of the community of practice which sustains their identity can also insulate them from outside influence and engagement (Wenger, 1988). Interaction across boundaries can divert teachers and gallery educators from well-trodden paths and habitual ways 
of thinking, creating the possibilities of hybrid practices which may on one hand lead nowhere but on the other hand, sow the seeds of revitalised or enhanced practice.

If practitioners from the two constellations of parallel communities of practice become more aware of their complementary identities, areas of power, influence and expertise through a recognition of the social processes by which their discourse and practice is constructed, they will be more able to approach each other and engage. Recognising and understanding difference and the processes through which different identities are constructed and negotiated seems fundamental to fruitful, respectful collaboration. Understanding the potential of boundary practices to develop the three key dimensions of mutual engagement, joint enterprise, and shared repertoire could result in the formation of new alliances and partnerships. The new trans-institutional and inter-professional communities of practice formed could draw art teachers and gallery educators together in new forms of engagement negotiating new identities, discourse and practice across boundaries in the shared enterprise of education.

Acknowledgements

I would like to thank Bridget McKenzie my co-researcher and Dennis Atkinson and Carrie Paechter who both gave very helpful feedback on earlier drafts of this paper.

\section{Correspondence}

Steve Herne, Department of Educational Studies, Goldsmiths College, University of London, New Cross, London SE14 6NW, United Kingdom

(s.herne@gold.ac.uk) 


\section{References}

Amidu, M. (2001) Report on the Third Year of SWAP (Schools and Whitechapel Artists' Programme). London: Whitechapel Art Gallery. Online, Available HTTP: http://www.whitechapel.org/download/swapnewsletter/swapstories/reports.html (14.03.04).

Anderson, D. (1997, 1999) A Common Wealth: museums in the learning age. London: Department for Culture Media and Sport (DCMS).

AQA (2000) General Certificate of Secondary Education. Art and Design. Full and Short Course. Specification 2003. Surrey: AQA Publications.

Bennet, C. (1985) Paints, Pots or Promotion? Art Teachers' Attitudes Towards Their Careers, in S. J. Ball and I. F. Goodson Teachers' Lives and Careers. London: The Falmer Press.

Dalton, P. (2001) The Gendering of Art Education. Buckingham: Open University Press.

Efland, A., K. Freedman, et al. (1996). Post Modern Art Education: An Approach To Curriculum. Virginia: National Art Education Association.

Glaser, B. and A. Strauss (1967) The Discovery of Grounded Theory, Chicargo: Aldine Publishing Company.

Goodson, I. F. (1985) Social Histories of the Secondary Curriculum. London: Falmer. 
GTTR (2003) GTTR accepted applicant statistics 22/08/2003. 2003 English statistics, Graduate Teacher Training Agency. Online, Available HTTP:

http://www.gttr.ac.uk/stats03/accs220803.html (14.03.04).

Harris, J. (2001) The New Art History. A critical Introduction. London: Routledge.

Herne, S. (1998) New Patterns of Museum and Gallery Education. London: London Association for Art and Design Education.

Herne, S. (2001) Report on the Second Year of SWAP (Schools and Whitechapel Artists' Programme). London: Whitechapel Art Gallery. Online, Available HTTP: http://www.whitechapel.org/download/swapnewsletter/swapstories/reports.html (14.03.04).

Howarth, D. (2000) Discourse. Buckingham: Open University Press.

Kuhn, T. $(1962,1970)$ The Structure of Scientific Revolutions. Chicago: University of Chicago Press.

Laclau, E. and C. Mouffe (1985) Hegemony and Socialist Strategy. London: Verso.

Lave, J. and E. Wenger (1991) Situated Learning. Cambridge: Cambridge University Press.

Mason, R. (1990) Art and Multicultural Education: the New Ethnicity in the UK, Journal of Art and Design Education (JADE) 9(3), pp. 329-339. 
McKenzie, B. (2001) Working with Schools on the Problems of Looking, engage review, 8, pp. 22-26.

Rees, A. L. and F. Borzello, Eds. (1986) The New Art History. London: The Camden Press.

Selwood, S. and S. Clive (1992) Substance and Shadow. London: London Arts Board Publications.

Shulman, L. S. (1986) Those who understand: Knowledge growth in teaching, Educational Researcher, 15, pp. 4-14.

Star, S. L. (1989) The structure of ill-structured solutions: boundary objects and heterogeneous distributed problem solving, Working Paper, Department of Information and Computer Science. Irvine: University of California.

Wenger, E. (1998) Communities of Practice. Learning, Meaning and Identity. Cambridge: Cambridge University Press. 